\title{
To Migrate or to Commute?
}

\author{
STEFAN GRUBER ${ }^{* \dagger}$ \\ UMIT - Institute for Health Economics and Management, RCEA and Austrian \\ Center for Labor Economics and the Analysis of the Welfare State
}

\begin{abstract}
In this paper, we investigate the agglomeration patterns in a New Economic Geography model when commuting is allowed. The introduction of both commuting and housing costs leads to a disentangling of the agglomeration of firms and people. Commuting allows workers to continue living in agglomerations and enjoying the benefits of a larger product variety, despite high housing costs, since they may choose to commute to another place where they receive higher wages, which in turn enables them to cover high housing costs at their place of living. This observation is especially true for skilled workers, who generally are more mobile than unskilled workers.
\end{abstract}

Keywords: New Economic Geography, Commuting, Mobility of workers, Commuting costs, Housing costs

JEL Classifications: F12, F14, R12

\section{Introduction}

At London's highly frequented Victoria Station, in 2008, about 70,000 passengers entered the underground during the morning peak on average. About 80 million people were using just this single underground station in that year. By 2016, Transport for London expects this number to increase up to 100 million annual passengers at Victoria ${ }^{1}$. The New York City Transit has over 7.4 million daily passengers on average in its network in New York City in $2008^{2}$. De Bruyne (2006) finds that about $50 \%$ of the working population in Belgium commute to work into another municipality than the one of residence, and about $27 \%$ of the working population

*I would like to thank Antonio Accetturo, Mario Larch, Luigi Marattin, Gianmarco Ottaviano, Michael Pfaffermayr, participants at the $1^{\text {st }}$ SOEGW Conference in Rimini, the TERA-project meeting in Joensuu, the $1^{\text {st }}$ GLUNLAB Workshop in Thessaloniki, and at a research seminar in Rimini for helpful comments and discussions. Of course, all the remaining errors are mine.

Financial support from the TERA-project funded by the European Commission within the $6^{\text {th }}$ Framework Programme of RTD (grant no. FP6-SSP-2005-006469) is gratefully acknowledged.

Corresponding address: UMIT - University for Health Sciences, Medical Informatics and Technology, Institute for Health Economics and Management, Eduard-Wallnoefer-Zentrum 1, A-6060 Hall in Tirol, Austria. Phone: +43-50-8648-3872, Fax: +43-50-8648-673872. E-mail: Stefan.Gruber@umit.at.

${ }^{1}$ See http://www.tfl.gov.uk/corporate/projectsandschemes/stationsandinterchanges/5140.aspx

${ }^{2}$ See http://www.mta.info/mta/network.htm\#statsnyct.

(C) 2010 Stefan Gruber. Licenced under the Creative Commons Attribution-Noncommercial 3.0 Licence (http://creativecommons.org/licenses/by-nc/3.0/). Available at http://rofea.org. 


\section{GRUBER To Migrate or to Commute?}

commute into another district. As these empirical facts suggest, commuting is necessary for many people for getting to work, but also for shopping or leisure activities. Thus we should care about those huge daily flows of people and investigate how they affect the economic landscape, the location of jobs (hence firms), and the economic 'evolution' of regions. In this sense, the present paper takes up a suggestion by Fujita and Krugman (2004), and tries to contribute to integrate urban features such as commuting into geographical models.

Glaeser and Kohlhase (2004) note that commuting costs are of decisive importance for the spatial shape of the economy, since transport costs have reached quite low levels nowadays. Of course, the 'pure' commuting costs have declined, just as transport costs did. But accounting for the time spent in commuting and its associated costs, they still remain quite substantial (see Glaeser and Kahn, 2004). Anas (2000) found that decreasing commuting costs may at least partly account for the increasing trend towards urban agglomeration, despite large population growth. In a study on the San Francisco Bay Area, Cervero and Wu (1998) find that commuting has gained its importance not only through falling costs, but also because of job decentralization, i.e., a relocation of firms away from the center into more suburban areas.

As to migration, especially in Europe both international and interregional migration rates are quite low. Puga (1999) notes that in the EU only about 1\% of the workers work outside their member state of origin. In a study on labor markets and the European currency union, Eichengreen (1993) estimated the elasticity of interregional migration with respect to the ratio of local wages to the national average to be about 25 times higher in the US than in the UK, and found an even larger difference, for instance, to Italy.

This paper accounts for these two different types of mobility for getting to work by incorporating commuting into a New Economic Geography (NEG) setting, while maintaining the usual mobility assumption (i.e., migration) for workers (see, e.g., Krugman 1991b; Fujita et al., 1999). We show that the agglomeration of industries and people (who are both, workers and consumers) may be disentangled, and now displays different intensities as measured by their relative regional shares. In particular, the agglomeration of people remains rather similar compared to the standard NEG-setting, whereas the agglomeration of production activities becomes less pronounced. This is due to the two main features of the model, (i) the possibility to commute as an additional type of mobility, and (ii) the introduction of housing and commuting costs for workers.

By including commuting and its associated costs, in connection with housing costs, we establish a link to the ample urban economics literature (such as Abdel-Rahman and Anas, 2004; Fujita, 1998; or Fujita and Thisse, 2002 for an overview). In this field of research, urban costs (represented by commuting costs) and housing costs play decisive roles in determining the location of residential zones, the central business district (CBD), or the development of subcenters within cities. Compared to the urban economics approach, and for a better intuition, the idea of the present paper is to look at a slightly larger geographic scale, i.e., at regions or cities 
(municipalities) located sufficiently close to each other, where both migration and commuting may turn out to be feasible ${ }^{3}$.

Previous NEG-literature has only paid rather scant attention to commuting in its theoretical models. Ottaviano et al. (2002) introduce an analytically solvable modelling framework, which departs from the love-of-variety specification following Dixit and Stiglitz (1977), and instead turns to a quasi-linear utility function, where love-of-variety is introduced by a quadratic subutility function. They show that commuting following the urban economics literature (see Abdel-Rahman and Anas, 2004, for an overview) can be incorporated into this setting. Ottaviano et al. (2002) find that any positive commuting costs lead to divergence provided that transport costs are low enough, and that high commuting costs always lead to dispersion of both firms and population. Additionally, agglomeration becomes less optimal as commuting costs rise.

Tabuchi and Thisse (2006) provide a model-setup, where they force consumer-workers to commute in order to get to work. They use a model with three factors, one homogenous and costlessly tradable good, a horizontally differentiated manufacturing good, and land (or housing). Similarly to Ottaviano et al. (2002), each consumer-worker consumes one unit of land and has to commute to the CBD to work at some cost, whereas firms are not assumed to consume land. However, Tabuchi and Thisse (2006) disregard the agricultural sector but include urban costs as a dispersion force. Also product differentiation acts as a dispersion force when all consumers are mobile, whereas price competition is exactly the opposite and fosters agglomeration since workers have to be compensated for the higher urban costs of living centrally. Additionally, in Tabuchi and Thisse (2006) commodity-specific transport costs may lead to equilibria where one sector is agglomerated and the other one partially dispersed. In general, high transport costs lead to agglomeration.

Murata and Thisse (2005) aim at a similar objective, employing the same modelling framework. Here, people live in two cities, where they have to commute into the CBD for work. People may choose to migrate into the other city whenever they can achieve a higher indirect utility. Murata and Thisse (2005) show that the standard NEG-results that high transport costs for goods lead to agglomeration (as in Fujita et al., 1999; Krugman, 1991b) may be reversed, as commuting costs are introduced. Now, high transport costs and low commuting costs lead to agglomeration, whereas high transport costs for goods lead to dispersion of both people and firms across the two cities. Agglomeration is also sustainable for low values of transport costs provided that commuting costs are also sufficiently low. These effects arise through the interplay of both, transport and commuting costs. In the Murata and Thisse (2005) setting, workers

\footnotetext{
${ }^{3}$ Note that the introduction of commuting in this paper is similar to the urban economics approach (i.e., workers getting from their place of living to their place of work), and we sort of add this feature into a NEG-model. From an urban economics perspective, we add the opportunity for workers to move to another place, city, or region.
} 


\section{GRUBER To Migrate or to Commute?}

benefit from being agglomerated by saving on transport costs for the goods but have fewer varieties, whereas being dispersed has opposite effects.

In a more urban economics oriented framework, Mascarilla Miro and Yegorov (2005) aim at creating a model of an optimal city with respect to size as a function of urban costs and benefits by taking into account commuter flows and migration. Since commuting has become very attractive for people due to reduced costs, they find that one may never be able to find a long-run stable equilibrium configuration of city size. The presence of some migration and commuter flows is an indication for an asymmetric equilibrium.

Another important property of commuting is that it may act like a safety valve for high housing costs close to the place of work. If the costs of living more remotely plus the commuting costs (including transport, time, etc.) are below the housing costs of living centrally, it pays off to live more apart from the center and to commute. Commuting costs plus the associated time spent in commuting are frequently referred to as urban costs (see for instance Tabuchi and Thisse, 2006). This, of course, releases some pressure off the housing market in the center (see, e.g., Cameron and Muellbauer, 1998). However, commuting can cause negative welfare-effects (congestion effects), if it causes delays, traffic jams, or environmental damage ${ }^{4}$.

Again, we want to emphasize that our model is capable of dealing with those two important properties of commuting, i.e. being (i) an alternative to migration, and (ii) a means to cope with housing costs. Our analysis shows that the different types of mobility of people (move, commute, stay) yield core-periphery patterns which depart from standard NEG-predictions in the sense that the agglomeration of firms becomes less pronounced than that of people. This is a consequence of the introduction of commuting as an additional way of being mobile. Commuting allows workers to continue living in agglomerations and enjoying the benefits of a larger product variety, despite high housing costs, since they may choose to commute to another place (another region) where they receive higher net-of-commuting-costs wages, which in turn enables them to cover the high housing costs at their place of living. This observation is especially true for skilled workers, who generally are more mobile than unskilled workers. In contrast to the previously cited literature, consumers/workers are not forced to commute in the present model, but they may do so if they find it rational. Hence, a worker/consumer has three options of being mobile - to move, to commute, or to stay.

The remainder of the paper is organized as follows: Section 2 introduces the model, Section 3 briefly lines out the analyses being conducted. Sections 4-6 analyze the core-periphery patterns, the influence of commuting on industry-shares, and its effects on the agglomeration of firms and people for our three basic scenarios, which are unskilled labor mobility, skilled labor mobility and the mobility of both types of workers. Finally, we turn to investigate the robustness of our model (Section 7), while the last Section summarizes and concludes.

\footnotetext{
${ }^{4}$ A good example for such a situation is the city of Atlanta (GA), where average commutes are quite long (34 miles or about $55 \mathrm{~km}$ ) and the rush-our lasts more or less all day long (The Economist, 1999b). Also in Chicago, $11 \%$ of the population commute at least 60 minutes to work one way (The Economist, 1999a).
} 
Review of Economic Analysis 2 (2010) 110-134

\section{The Model}

\subsection{Households}

There are two regions, referred to as regions 1 and 2, and indexed as $\{i, j\}=\{1,2\}$. In order to obtain a good sketch of the regions' economies in the model, both regions produce three goods, $Z, X$ and $D$, reflecting the three main economic sectors. $Z$ is a homogenous agricultural good produced at constant returns to scale by a competitive industry. $X$-goods (manufacturing goods) are differentiated in the usual Dixit-Stiglitz-fashion (see Dixit and Stiglitz, 1977). Firms may sell on the local market and export to the other region, where the number of firms from region $i$ is denoted by $n_{i}$. Therefore, $X_{i j}$ are the exports of region $i$-based firms to region $j .{ }^{5} X_{i c}$ denotes the consumption of $X$ in region $i$, being a CES aggregate of the individual varieties. $D$ are homogenous, non-tradable and region-specific services produced competitively at constant returns to scale. $D_{i}^{n c}$ denotes the services consumed and produced in region $i$ by non-commuters, and $D_{i}^{c i}+D_{j}^{c i}$ is the amount of services consumed by commuters from region $i$, who are allowed to allocate a fraction $(\delta)$ of their income spent on services to buy services at their place of work $\left(D_{j}^{c i}\right)$ - imagine going to the hairdresser's or eat lunch at the place of work. The remaining fraction of income devoted to services consumption, $1-\delta$, is spent at the place of living $\left(D_{i}^{c i}\right)$. The utility of region $i\left(U_{i}\right)$ can thus be formulated as follows:

$$
\begin{aligned}
U_{i} & =X_{i}^{\alpha}\left[D_{i}^{n c}+\left(D_{i}^{c i}+D_{j}^{c i}\right)\right]^{\beta}\left(Z_{i i}+Z_{j i}\right)^{1-\alpha-\beta}, \\
X_{i c} & \equiv\left[n_{i}\left(X_{i i}\right)^{\frac{\sigma-1}{\sigma}}+n_{j}\left(\frac{X_{j i}}{1+\tau}\right)^{\frac{\sigma-1}{\sigma}}\right]^{\frac{\sigma}{\sigma-1}},
\end{aligned}
$$

where $\alpha$ denotes the Cobb-Douglas expenditure share for differentiated products, $\beta$ the one for services, and $\sigma>1$ is the elasticity of substitution between varieties of the manufactured good.

We assume that $Z$-goods are costlessly tradable across regions, whereas $X$-goods trade incurs iceberg transport costs $(\tau)$, which are symmetric for either direction of shipment. In terms of quantity, one unit of consumption of an $X$-variety in region $j$ requires a firm in $i$ to send $(1+\tau)$ units. For convenience, quantities of $X$ are defined as firm-specific productions for the respective foreign market.

As usual, the consumer's maximization problem can be solved in two steps. In the first step, each variety $X_{j i}$ needs to be chosen such that it minimizes the cost of attaining $X_{i c}$, whatever the consumption of $X_{i c}$ is. In the second step, consumers allocate income between the $Z$-good, the services $(D)$, and the composite $X$-good. Let $p_{j i}$ be the price of an $X$-variety in region $i$ produced by a firm in region $j$. The price for the homogenous agricultural good, $q_{i}$, is indexed once, since all (indigenous and foreign) homogenous goods consumed at a single location $i$ must face the same price $q_{i}$. Similarly, the price of services, $r_{i}$, is equal no matter whether local residents or inward-commuters consume services in region $i$. We take $q_{1}$ as the numéraire. Further, $P_{i}$

${ }^{5}$ Whenever we use $i$ and $j$ from the set $\{1,2\}$, this implies that $i \neq j$. 


\section{GRUBER To Migrate or to Commute?}

denotes the price aggregator, defined as the minimum cost of buying one unit of $X_{i}$ at prices $p_{j i}$ of an individual variety:

$$
P_{i}=\min _{X_{j i}} \sum_{i, j} p_{j i} X_{j i} \quad \text { s.t. } \quad X_{i}=1 .
$$

The first-stage budgeting problem leads to:

$$
X_{j i}=\left(p_{j i}\right)^{-\sigma} P_{i}^{\sigma-1} \alpha Y_{i} \quad \forall \quad i, j \in\{1,2\},
$$

where $Y_{i}$ denotes total expenditures of consumers in region $i$, and $p_{j i}=p_{j}(1+\tau)$, i.e., the local goods price in region $j\left(p_{j}\right)$ including transport costs $(1+\tau)$. Identical price elasticities of demand and identical marginal costs (technologies) within a region ensure that the price of a locally produced manufacturing good is equal to the mill price for exports. Hence, prices of all manufacturing goods produced in one region are equal in equilibrium. $p_{i}$ denotes the price of all goods produced in region $i$. With these assumptions, the price aggregator $P_{i}$ of differentiated goods consumed in region $i$ can be written as

$$
P_{i}=\left[n_{i} p_{i}^{1-\sigma}+n_{j}\left((1+\tau) p_{j}\right)^{1-\sigma}\right]^{\frac{1}{1-\sigma}} .
$$

The second-stage budgeting yields the division of expenditures among the three sectors:

$$
\begin{aligned}
X_{i} & =\frac{\alpha}{P_{i}} Y_{i} \\
D_{i}^{n c}+D_{i}^{c i}+D_{j}^{c i} & =\frac{\beta}{r_{i}} Y_{i} \\
Z_{i i}+Z_{j i} & =\frac{1-\alpha-\beta}{q_{i}} Y_{i}
\end{aligned}
$$

\subsection{Commuters}

The basic idea is to look at commuting across cities or regions, which means that we are looking at two neighboring regions where an individual may consider it as feasible and rational to commute on a daily basis. Workers living in region $i$ will decide to commute if their nominal wage net of commuting costs in region $j$ is larger than their nominal wage in region $i$.

The set of strategies of mobility patterns available for consumers/workers in the present model is as follows (see also Figure 1): Firstly, workers decide where to work by comparing net-of-commuting costs wages, and secondly where to live by comparing real wages across regions. In other words, people first look for a job and then decide where to live. Hence, the integration of commuting into this paper sort of precedes the standard Krugman-type mobility decision, and probably reflects the usual mobility pattern of people, at least in Europe: before moving to another city for a new job, one decides to commute and continues living at the same place. Following this basic decision logic, three options arise: ${ }^{6}$ (i) live and work in region

${ }^{6}$ Figure 1 shows these options, from the left until the vertical line in the diagram. 
Figure 1: Decision Tree for Consumer's/Worker's Mobility.

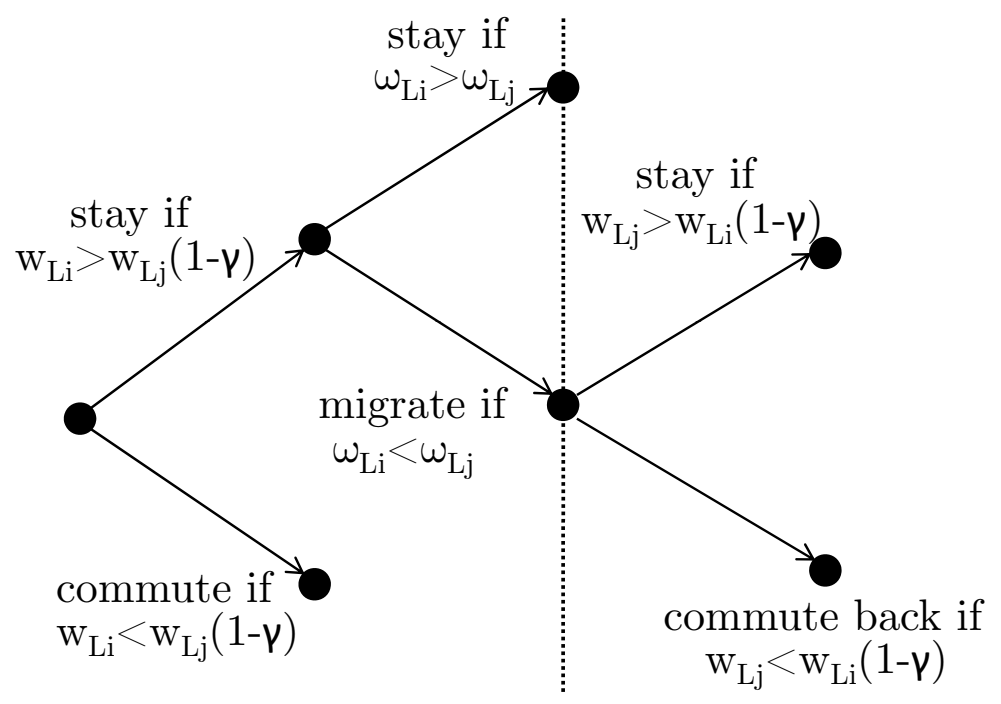

1, (ii) live in region 1 and commute to region 2 for work, (iii) move to region 2 and work there. Intuitively, there is a fourth strategy for consumers/workers ${ }^{7}$, which would require a two-period model to be fully captured. The main reason is that the standard NEG-model looks at instantaneous changes of equilibria, and not at adjustment process between two long-run stable equilibria. The decision to move away from the home region 1 into region 2 and then to commute back into region 1 for work would require to look at this adjustment process. In other words, this strategy involves two decision processes of the kind lined out in the previous paragraph. On the other hand, the remaining three strategies (move, commute, stay), which are the ones being addressed in the paper, only require to run through one such decision process. In the paper, we do not address this fourth possible strategy explicitly, since we cannot track this possibility within our model ${ }^{8}$.

Let $w_{L i}, w_{S i}$ and $w_{T i}$ denote the factor rewards for unskilled labor, skilled labor, and land in region $i$, respectively. In region $i$, the group of $L_{i}+S_{i}$ workers, is split into people who live and work in $i\left(L_{i i}+S_{i i}\right)$, and people who live in $i$ but commute to work into region $j\left(L_{i j}+S_{i j}\right)^{9}$. Commuters incur some iceberg-type commuting costs, $\gamma$, reducing their wage, such that the wage net of commuting costs for a commuter from $i$ to $j$ is $(1-\gamma) w_{L j}$ or $(1-\gamma) w_{S}$, respectively.

${ }^{7}$ Figure 1 shows also this option, to the right of the vertical line in the diagram.

${ }^{8}$ The decision of once having moved from region 2 and then to commute back into region 1 would also feed back into to remaining process of workers deciding where to work and to live, and might thus lead decisions taken by others to be not optimal and hence also no long-run stable equilibrium.

${ }^{9}$ The first subscript denotes the place of living, the second subscript the place of work of people. 


\section{GRUBER To Migrate or to Commute?}

Hence, the commuting conditions for skilled and unskilled workers are as follows:

$$
\begin{array}{lll}
w_{L i} \geq w_{L j}(1-\gamma) & \perp & L_{i j} \geq 0, \\
w_{S i} \geq w_{S j}(1-\gamma) & \perp & S_{i j} \geq 0,
\end{array}
$$

where $\perp$ indicates that at least one of the adjacent conditions has to hold with equality. The commuters live in their home region $\left(L_{i j}\right.$ and $S_{i j}$ in region $i, L_{j i}$ and $S_{j i}$ in region $j$ ), cover their housing costs there, and spend most of their income in their home region. Recall that commuters are also allowed to spend a fraction $(\delta)$ of their income devoted to services $(\beta)$ in their region of work.

In order to cover the workers' need for housing space, they consume one unit of immobile land $\left(T_{i}\right)$. Hence, the associated housing costs are $w_{T i}$. Workers spend their money where they live, which means that the amount of people buying goods in region $i$ is $L_{i}+S_{i}$ plus the net of the inward and outward commuters' fraction of income spent at the place of work for services. The number of people employed in region $i$ is $L_{i i}+S_{i i}+L_{j i}+S_{j i}$, i.e., workers living and working in $i$, plus inward commuters, i.e., workers commuting from region $j$ into region $i$.

However, the commuting-decision alone would imply that either all workers commute or all workers do not. The corresponding centrifugal force comes from the requirement that all workers incur housing costs in terms of the immobile factor land $\left(T_{i}\right)$. We will return to this in

more detail in the next section. As in the standard NEG-models, we of course also allow for the usual opportunity of migration between regions according to higher real wages.

\subsection{Factor Markets, Production and Income}

Assuming that $Z$-production only uses land $(T)$, variable unit costs (i.e., marginal costs) $c_{Z i}$ satisfy

$$
c_{Z i} \geq w_{T i} \quad \perp \quad Z_{i i} \geq 0
$$

This implies

$$
c_{Z i} \geq q_{j} \quad \perp \quad Z_{i j} \geq 0 .
$$

$D$-production is also perfectly competitive, but with each firm producing under a CES technology, using unskilled $(L)$ and skilled $(S)$ labor (where ' $b$ ' is the coefficient for $S$ and ' $1-b$ ' for $L)$, with a technical rate of substitution of $1 /(1-\rho)(-\infty<\rho<1)$. The region specific unit input coefficient for the two factors of $D$-production can be derived by cost minimization subject to this CES technology:

$$
\begin{aligned}
& a_{S d i}=\left(\frac{w_{S i}}{b}\right)^{\frac{1}{\rho-1}}\left[\left(\frac{w_{S i}^{\rho}}{b}\right)^{\frac{1}{\rho-1}}+\left(\frac{w_{L i}^{\rho}}{1-b}\right)^{\frac{1}{\rho-1}}\right]^{-\frac{1}{\rho}} \\
& a_{L d i}=\left(\frac{w_{L i}}{1-b}\right)^{\frac{1}{\rho-1}}\left[\left(\frac{w_{S i}^{\rho}}{b}\right)^{\frac{1}{\rho-1}}+\left(\frac{w_{L i}^{\rho}}{1-b}\right)^{\frac{1}{\rho-1}}\right]^{-\frac{1}{\rho}}
\end{aligned}
$$


There is monopolistic competition in the $X$-sector, and again each firm produces under a CES technology, using unskilled labor and land $(T$ ) (where ' $a$ ' is the coefficient for $L$ and ' $1-a$ ' for $T)$, with a technical rate of substitution of $1 /(1-\rho)(-\infty<\rho<1)$. As all firms face the same factor prices and the CES technology is homothetic, all firms in a region face the same unit input coefficients. The region specific unit input coefficients for the two factors of $X$-production can be derived by cost minimization subject to this CES technology:

$$
\begin{aligned}
& a_{L x i}=\left(\frac{w_{L i}}{a}\right)^{\frac{1}{\rho-1}}\left[\left(\frac{w_{L i}^{\rho}}{a}\right)^{\frac{1}{\rho-1}}+\left(\frac{w_{T i}^{\rho}}{1-a}\right)^{\frac{1}{\rho-1}}\right]^{-\frac{1}{\rho}} \\
& a_{T x i}=\left(\frac{w_{T i}}{1-a}\right)^{\frac{1}{\rho-1}}\left[\left(\frac{w_{L i}^{\rho}}{a}\right)^{\frac{1}{\rho-1}}+\left(\frac{w_{T i}^{\rho}}{1-a}\right)^{\frac{1}{\rho-1}}\right]^{-\frac{1}{\rho}}
\end{aligned}
$$

Additionally, $X$-sector firms require unskilled labor $\left(a_{L n i}\right)$ and land to set up plants $\left(a_{T n i}\right)$, leading to increasing returns to scale in production.

Factor market clearing in region $i$ for labor $\left(L_{i}, S_{i}\right)$ and land $\left(T_{i}\right)$ requires

$$
\begin{aligned}
L_{i i}+L_{j i}(1-\gamma) \geq & a_{L x i}\left(n_{i} X_{i i}+n_{i} X_{i j}\right)+a_{L n i} n_{i}+ \\
& a_{L d i}\left(D_{i}^{n c}+D_{i}^{c j}+D_{i}^{c i}\right) \quad \perp \quad w_{L i} \geq 0, \\
S_{i i}+S_{j i}(1-\gamma) \geq & a_{S d i}\left(D_{i}^{n c}+D_{i}^{c j}+D_{i}^{c i}\right) \quad \perp \quad w_{S i} \geq 0, \\
T_{i} \geq & a_{T x i}\left(n_{i} X_{i i}+n_{i} X_{i j}\right)+Z_{i i}+Z_{i j}+ \\
& a_{T n i} n_{i}+L_{i}+S_{i} \perp \quad w_{T i} \geq 0 .
\end{aligned}
$$

Variable unit costs of producing an $X$-variety in region $i$ are given by $c_{X i}=a_{L x i} w_{L i}+a_{T x i} w_{T i}$. There is a fixed markup over variable costs, which is determined by the elasticity of substitution between varieties. Given that under CES-utility demand for all varieties is positive, we may write

$$
p_{i}=c_{X i} \frac{\sigma}{\sigma-1} .
$$

Free entry implies that firms earn zero profits, since operating profits are used to cover fixed costs. The corresponding zero profit condition determines the numbers of firms.

Firms in $i$ have to bear fixed costs of $F C_{n i}=a_{L n i} w_{L i}+a_{T n i} w_{T i}$. The zero profit condition, therefore, implies

$$
F C_{n i} \geq \frac{p_{i}\left(X_{i i}+X_{i j}\right)}{\sigma} \perp n_{i} \geq 0 .
$$

All factors are owned by the households, so that consumer income (i.e., GNP) net of commuting and housing costs in region $i$ is given by

$$
\begin{aligned}
Y_{i}= & {\left[w_{L i} L_{i i}+w_{L j}(1-\gamma) L_{i j}\right]+\left[w_{S i} S_{i i}+w_{S j}(1-\gamma) S_{i j}\right]-} \\
& w_{T i}\left(L_{i}+S_{i}\right)+w_{T i} T_{i}
\end{aligned}
$$




\section{GRUBER To Migrate or to Commute?}

The first two RHS-terms in square parenthesis constitute the income of all workers of each type living in region $i$, the third term captures the housing costs of workers, and the last term is the factor income of land. The equivalence of total factor income $\left(Y_{i}, Y_{j}\right)$ and demand in each region implicitly balances payments between regions.

Real factor rewards $(\omega)$ are normalized by region-specific costs of living, $P_{i}^{-\alpha} r_{i}^{-\beta} q_{i}^{\alpha+\beta-1}$, and are thus given by:

$$
\omega_{k i}=w_{k i} P_{i}^{-\alpha} r_{i}^{-\beta} q_{i}^{\alpha+\beta-1}, \quad k \in\{L, S, T\} .
$$

\section{Analyzing the Model}

In contrast to the standard NEG-models à la Krugman (1991b), production of the manufacturing good uses two input factors ( $L$ and $T$ ). In those models it is straightforward to assume that the factor used in the manufacturing sector is mobile across regions. In line with the literature, all factors are immobile in the short run. In the long run, we investigate situations where either $L$ (intensively used in the manufacturing goods production), $S$ (intensively used in services) or both types of labor are mobile. In addition to the standard mobility assumption in terms of migration, we include commuting in our analysis. In practice, this means that region $i$ - workers may choose to either (i) live and work at the same place (region $i$ ), (ii) live in region $i$ and commute to region $j$, or (iii) move to region $j$ to live and work there.

Based on the wage net of commuting costs, workers decide whether to commute or not. Those workers who do not commute are then left with the choice whether to migrate or not, which is decided by the real wage differential between the two regions (see also Figure 1). A long run equilibrium is defined similar to Krugman (1991b) by real wage equalization across regions $\left(\omega_{L i}=\omega_{L j}\right.$ if unskilled labor is mobile, $\omega_{S i}=\omega_{S j}$ if skilled labor is mobile, and $\omega_{L i}=\omega_{L j} \wedge \omega_{S i}=\omega_{S j}$ when both types of labor are mobile). The stability of this equilibrium is analyzed by exogenously reallocating one unit of unskilled or skilled labor, respectively, to the other region, and deriving the new short run equilibrium. Then, firms are allowed to enter and exit to avoid losses and to exploit profits. If this reallocation of labor results in a decline of the corresponding real wages in the immigration country, the initial equilibrium is stable. Otherwise, the initial equilibrium is unstable, because even more workers would have an incentive to migrate.

As already lined out briefly, we want to focus on the differences in the development of the agglomeration of firms and people. In our model, this becomes possible through the introduction of commuting and housing costs. That means, workers may find it worthwhile to commute to the other region and receive a higher wage there (i.e., net of commuting costs), and to continue to live in their home region. The higher wage may enable them to stay in their home region even when housing costs are higher than in the other region, as long as their disposable income for consuming goods is still positive after deducting housing costs. This feature of the model reflects the frequent observation, that people tend to be more reluctant to migrate than to 
commute when deciding where to work (particularly in Europe). Consequently, it becomes possible that the one-to-one relationship between the agglomeration of firms and people in standard NEG-models becomes disentangled to a certain extent. Hence, standard reasoning that workers follow firms and firms follow workers may not hold in this model. Put differently, these three options for people to decide on where to live and to work also reflect different degrees of mobility in general (stay, commute, or migrate), notwithstanding that all three decisions may be rational in equilibrium.

In our model, we analyze three different mobility settings. We always allow both types of labor to commute, and with respect to migration, we either allow $L$ or $S$ separately to be mobile (in order to reach comparability to the existing NEG-literature), and finally investigate simultaneous migration of $S$ and $L$. For all the scenarios analyzed, we let transport and commuting costs vary between $1 \%$ and $99 \%$ of the goods price and the nominal wage, respectively. Of course, as the commuting costs approach $100 \%$ of the nominal wage, commuting reaches zero $^{10}$.

The following analyses show three different things. The bifurcation diagrams illustrating the core-periphery patterns depict the places of living of people. For each of these bifurcation diagrams, we provide the corresponding diagrams of the industry shares per sector per region (as percentages of production volumes), and of the commuters (as percentages of the population). Combining these three features within each of the following scenarios enables us to identify the places of living and the places of work of the population, as well as the distribution of economic activities (i.e., production volumes) across regions ${ }^{11}$.

\section{Scenario 1: Unskilled Labor Migration}

\subsection{Agglomeration of People}

This first scenario is the one which is most closely comparable to the two-sector and twofactor NEG-models following Krugman (1991a,b). This is because we are now looking at the mobility of the production factor which is intensively used in manufacturing. Thus, in the case of unskilled labor mobility, we obtain an agglomeration pattern which shows some similarities to Puga's (1999) bell-shaped agglomeration pattern. In our model, only the bifurcation diagrams of the resulting core-periphery patterns show similarities to Puga (1999), while the underlying

\footnotetext{
${ }^{10} \mathrm{We}$ have chosen the following parameter values for our simulations: $\sigma=4, \alpha=0.4, \beta=0.55$, $a=b=0.6, \rho=-10, L=L_{1}+L_{2}=100, S=S_{1}+S_{2}=30, T=T_{1}+T_{2}=400$, with the immobile factors being equally distributed across regions, unless anything else is mentioned. Note that we have chosen the income-expenditure shares for each sector such that they roughly correspond to modern industrialized and service-oriented economies. For simplicity, we assume $\gamma$ and $a$ to have the same values for $S$ and $L$, and $X$ and $D$, respectively.

${ }^{11}$ In the following three sections, analyzing the three main scenarios, we do not depict all the analyses conducted for each of them. We rather focus on the most illustrative issues, in order to keep the paper as compact as possible.
} 


\section{GRUBER To Migrate or to Commute?}

structure of the model is different. However, some of the reasoning is similar, since Puga (1999) looks at scenarios with and without migration, while the present analysis looks at cases with and without commuting. To make this clear, the bifurcation diagram of Figure 2 showing the core-periphery pattern for $L$-mobility is split into three parts ${ }^{12}$. Starting on the left at low transport and commuting costs (until $\tau=\gamma \approx 0.32$ ), either a symmetric equilibrium or partial agglomeration may occur ${ }^{13}$. In other words, the economy may either end up in a convergence (i.e., the symmetric equilibrium), or in a divergence setting (i.e., the partially agglomerated equilibrium). Which equilibrium prevails is determined endogenously (see Krugman's "history matters" in Krugman, 1991a). At intermediate transport and commuting costs $(0.32 \lesssim \tau=$ $\gamma \lesssim 0.84$ ), the only long-run stable equilibrium outcome is partial agglomeration, which is fully in line with Puga's (1999) results. This means, intermediate values of $\tau$ and $\gamma$ for sure lead to divergence between the two regions. Finally, high transport and commuting costs (from $\tau=\gamma \approx 0.84$ onwards) lead to a weakly partially agglomerated equilibrium configuration with weakening agglomeration as transport and commuting costs rise. The reason is that housing costs rise as the agglomeration becomes larger, and may even outweigh the advantages of having access to a large market, such that there are incentives for people to re-disperse. Thus, also here we qualitatively obtain Puga's (1999) results in a sense that high transport costs lead to convergence across regions, since it makes sense for firms to serve their markets locally in order to avoid transport costs. Except from the very right of this bifurcation diagram, here there is no symmetric equilibrium, which is a result of the production technology assumptions and of the introduction of commuting.

Rephrasing these results, the agglomeration patterns described above (see Figure 2) depict the places of living of people. For instance, at equilibria with $\lambda_{L i}=0.5$, half of the population of unskilled workers live in each region, and also half of the skilled workers live in each region.

Enlarging the analysis, and using Figure 2 in combination with Figure $3^{14}$, allows to identify the places of work of people. For instance, if region $i$ is small in terms of unskilled labor, about $8 \%$ of unskilled workers live and work in region $i$, and the remaining 92\% in region $j$ (see Figure 2). Skilled workers are only allowed to commute in this first scenario. Our analysis shows that more than $50 \%$ of the skilled workers of region $i$ commute to region $j$, which means that at least $75 \%$ of all skilled workers work in region $j$ (see Figure 3, right panel) ${ }^{15}$. Thus, as far as skilled workers are concerned, their places of living are dispersed, while their places of work are quite agglomerated.

\footnotetext{
${ }^{12}$ In all the bifurcation diagrams, solid lines denote long-run stable equilibria, whereas dotted lines depict unstable equilibria.

${ }^{13}$ Note that in the following we write ' $\tau=\gamma$ ' only because the simulations were run with simultaneous changes of transport costs $(\tau)$ and commuting costs $(\gamma)$.

${ }^{14}$ Figure 3 shows the commuting patterns for this scenario for both types of workers.

${ }^{15} \mathrm{All}$ the figures depicting where commuting occurs (i.e. Figures 3, 8, and 11) only indicate whether there
} 
Review of Economic Analysis 2 (2010) 110-134

Figure 2: Core-periphery Pattern with Mobile Unskilled Labor and $\lambda_{S}=\lambda_{T}=0.5$.

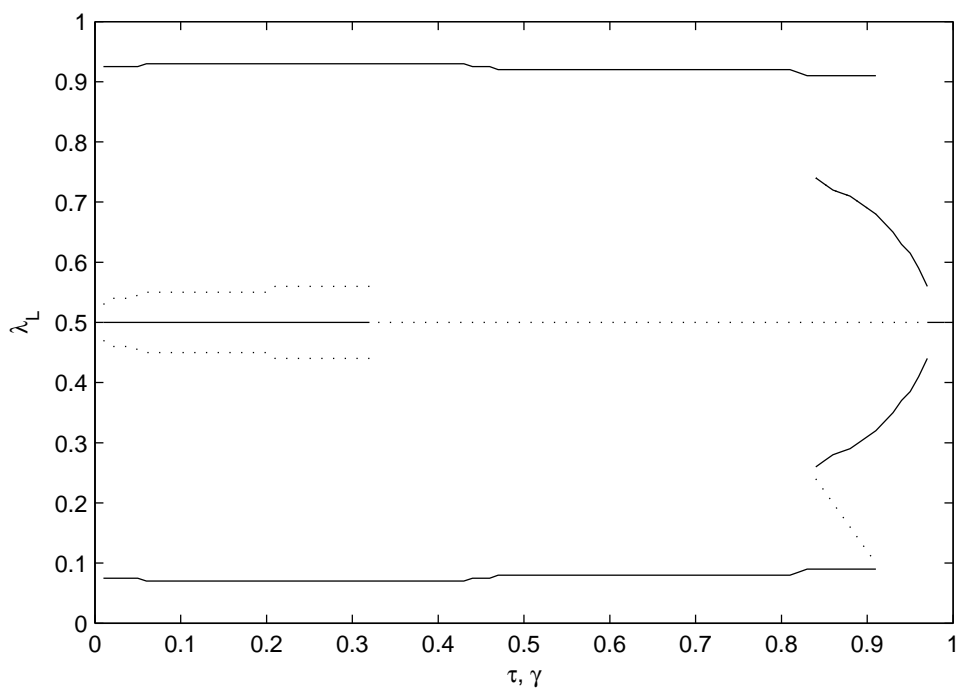

Figure 3: $L$-commuters (left) and $S$-commuters (right) Corresponding to Figure 2.
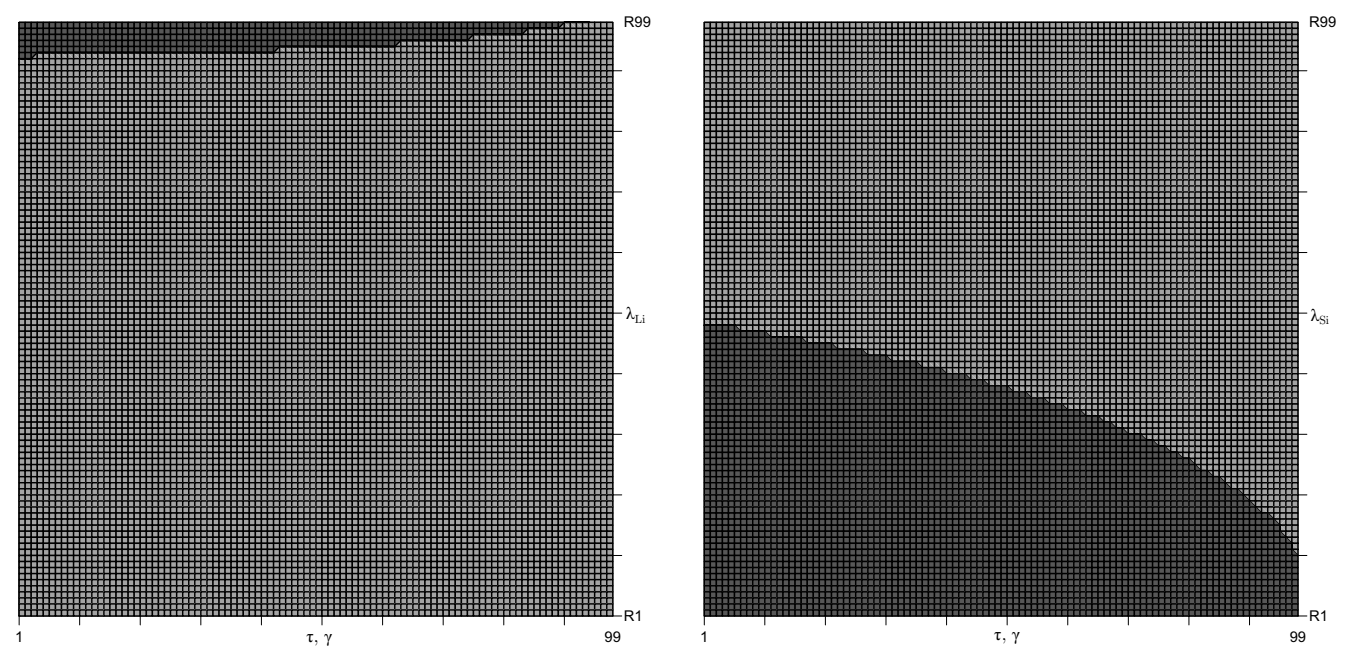

\subsection{Commuters}

In this scenario, $L$-workers only commute when their home region $i$ is very large, whereas $S$ workers commute when region $i$ is small (in terms of the mobile factor $L$ ). Commuting is not that important for $L$-workers since they also have the opportunity to migrate. Furthermore,

are commuters (the dark-grey areas) or not (the light-grey areas), they are not informative with respect to commuting volumes or percentages. The percentages mentioned are taken out of the simulation results. 


\section{GRUBER To Migrate or to Commute?}

unskilled labor wages are usually lower than skilled labor wages, and hence commuting costs play a larger role. Thus, unskilled workers only decide to commute when region $i$ is very large, and hence housing cost are very high. Only up to $8 \%$ of unskilled workers commute. For $S$ workers it makes sense to commute to region $j$ if region $i$ is small in terms of $L$, since in this case, region $j$ is the large one and thus requires a large amount of skilled workers in order to produce all the services demanded ( $D$-goods). That means, $S$-workers from region $i$ receive a higher wage in region $j$ and additionally benefit from the comparatively low housing costs in their home region. Hence, up to about $70 \%$ of skilled workers choose to commute.

Disallowing commuting for unskilled (skilled) workers, skilled (unskilled) workers commute to a larger extent, where this increase is stronger for skilled workers. Of course, as commuting costs rise, the number of workers who commute decreases. Disallowing commuting at all (see Figure 4), again leads to a replication of the bell-shaped agglomeration pattern of Puga (1999). Here, there is a long-run stable symmetric equilibrium (i.e., convergence across regions) both for low and prohibitively high transport and commuting costs $(\tau=\gamma \lesssim 0.32$, as well as $\tau=\gamma \gtrsim 0.97$ ). The same core-periphery pattern occurs when disallowing $S$-commuting only. This is due to fact that in the case of mobile $L, L$-commuting is of less importance, and thus the difference between no commuting at all and no $S$-commuting only becomes unobservable. Subsequently, by disallowing $L$-commuting only, the qualitative results regarding the core-periphery patterns obtained are the same as in the reference case with both types of commuting being allowed.

Figure 4: Core-periphery Pattern Corresponding to Figure 2, Without Commuting and $\lambda_{S}=\lambda_{T}=0.5$.

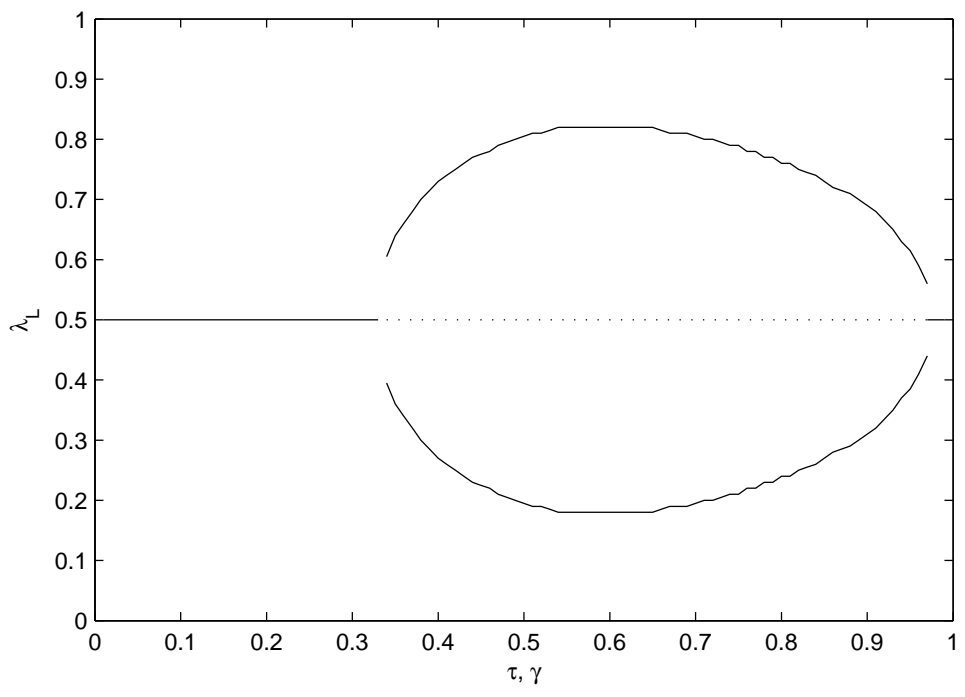




\subsection{Agglomeration of Firms}

Next, we look at the corresponding agglomeration of firms in each region in the long-run stable equilibria of the core-periphery patterns by computing the relative industry-shares for all the three sectors $(X, D$, and $Z)$. Still sticking to our unskilled labor mobility scenario, the importance of commuting for all the three sectors is especially observable at lower transport and commuting costs (until about $\tau=\gamma \approx 1 / 3$ of the goods price and of the nominal wage, respectively). Note that this range of transport costs corresponds to the empirically relevant range of these costs (see, e.g., Baier and Bergstand, 2001). Commuting affects the distribution of sectors between the regions in a somewhat diverging way, in particular the service sector (see Figure 5). This means, commuting induces the distribution of industries to be more unequal as the size of the regions in terms of the mobile factor (unskilled labor in this case) varies. In other words, in terms of production volumes, there is divergence. This is true at most values of $\lambda_{L i}$, whereas at extreme differences in the size of regions, commuting leads to convergence (compare the leftand righthand panel of Figure 5). At higher values of transport and commuting costs, this effect diminishes since commuting becomes less attractive due to higher costs. As a result, industries are generally less concentrated due to high transport costs. Thus, each region's share of industries is higher than in the non-commuting scenarios. These observations hold true for all the three economic sectors in the model. Since skilled workers may only commute but not migrate in this scenario, this diverging effect of commuting is strongest for skilled workers and thus for the service sector (see Figures 5 and 6) ${ }^{16,17}$.

Looking at the production values instead of production volumes, it turns out that the value of the services and manufacturing goods produced is higher in the case where commuting is allowed than in the non-commuting case, despite the lower production volumes.

\section{Scenario 2: Skilled Labor Migration}

In the case of mobile skilled labor, i.e., skilled labor is allowed both to migrate and to commute, full agglomeration in one region is the only long-run stable equilibrium for all values of transport costs (see Figure 7). That means, there is always divergence between regions, and the symmetric (i.e., convergence) equilibrium always remains unstable. This is fully in line with the higher degree of mobility, and with the observed agglomeration-tendency of skilled labor (see for instance Egger et al., 2007; Ottaviano and Thisse, 2002; Shields and Shields, 1989). Empirically, not only the higher degree of mobility of skilled workers is observable, but also that skilled workers are ready commute longer distances than unskilled workers (see for instance

\footnotetext{
${ }^{16}$ Note that we only show the graphs for the service sector, where the effect is largest.

${ }^{17}$ Figures 6, 9, and 12 depict the differences in production volumes for the three major scenarios between cases where commuting is being allowed and cases without commuting. In all these diagrams, the lightgrey areas indicate that production volumes are higher when commuting is allowed. The opposite applies for the medium-grey areas, whereas there are no differences in production volumes in the dark-grey areas.
} 


\section{GRUBER To Migrate or to Commute?}

Figure 5: Volume of $D$-production in Region $i$ with (left panel) and Without Commuters (right panel), $L$ mobile.
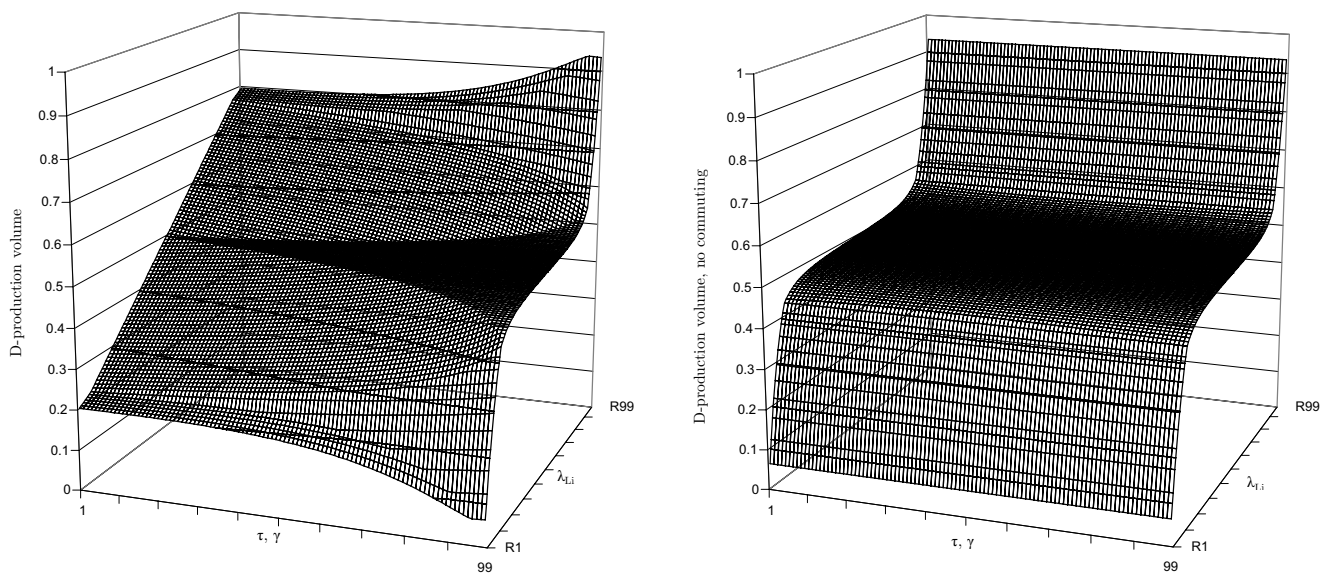

Figure 6: Difference in $D$-production Volumes in Region $i$ between the Left- and Righthand Panels of Figure 5, $L$ mobile.

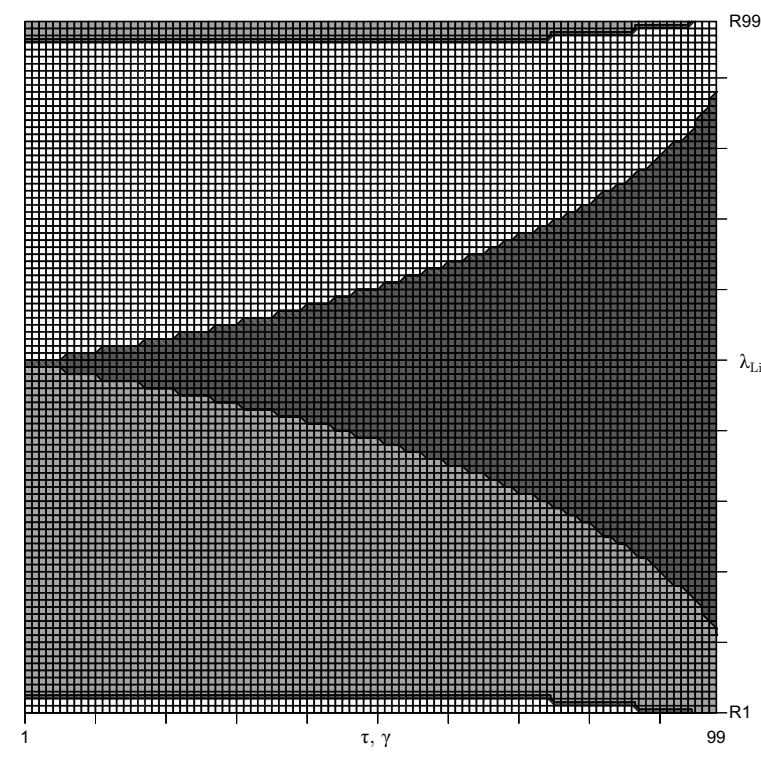

Cörvers and Hensen, 2003; Kertesi, 2000). Skilled workers commute if their home region is very large at decreasing rate as commuting costs rise, but with a constant fraction of up to $40 \%$ of the skilled workers from region $i$ (see Figure 8).

Comparing this to the non-commuting setting shows that disallowing commuting has no ef- 
Review of Economic Analysis 2 (2010) 110-134

Figure 7: Core-periphery Pattern with Mobile Skilled Labor and $\lambda_{L}=\lambda_{T}=0.5$.

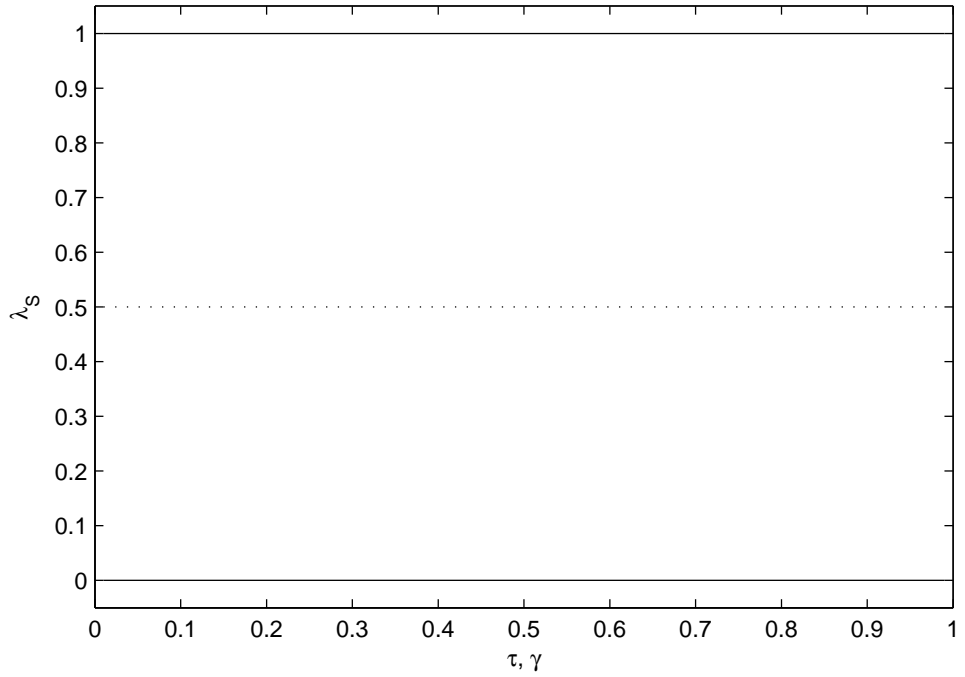

Figure 8: $S$-commuters Corresponding to Figure 7.

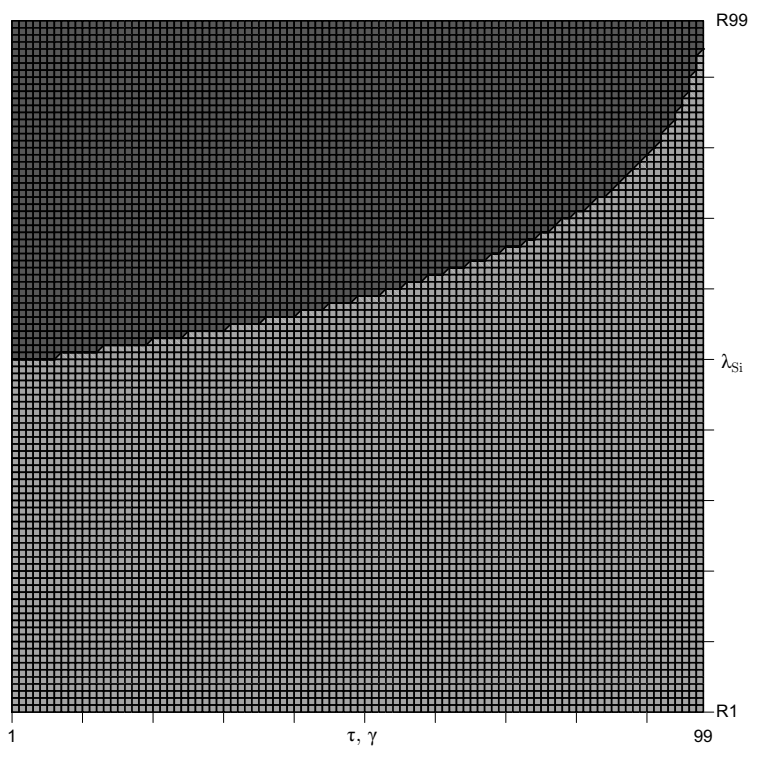

fects on the resulting agglomeration structure. However, it has some impact on the distribution of firms between the two regions. Without commuting, the distribution of firms becomes proportional to the number of workers living in each region, just as in the non-commuting case for unskilled labor mobility, while the full agglomeration core-periphery-pattern remains stable. 


\section{GRUBER To Migrate or to Commute?}

This again confirms that introducing commuting into a NEG-model disentangles the agglomeration of firms and people.

With mobile skilled labor $(S)$, however, there is a different result regarding the influence of commuting on the agglomeration of firms and people than in the case of unskilled labor mobility. In terms of the production volumes of services $(D)$, the possibility of commuting equalizes the distribution of economic activity among regions (see Figure 9), since services are assumed to be demanded locally. Figure 9 shows the differences in production volumes between the

Figure 9: Difference in $D$-production Volume in Region $i$ between the Commuting and the Non-commuting case, $S$ mobile.

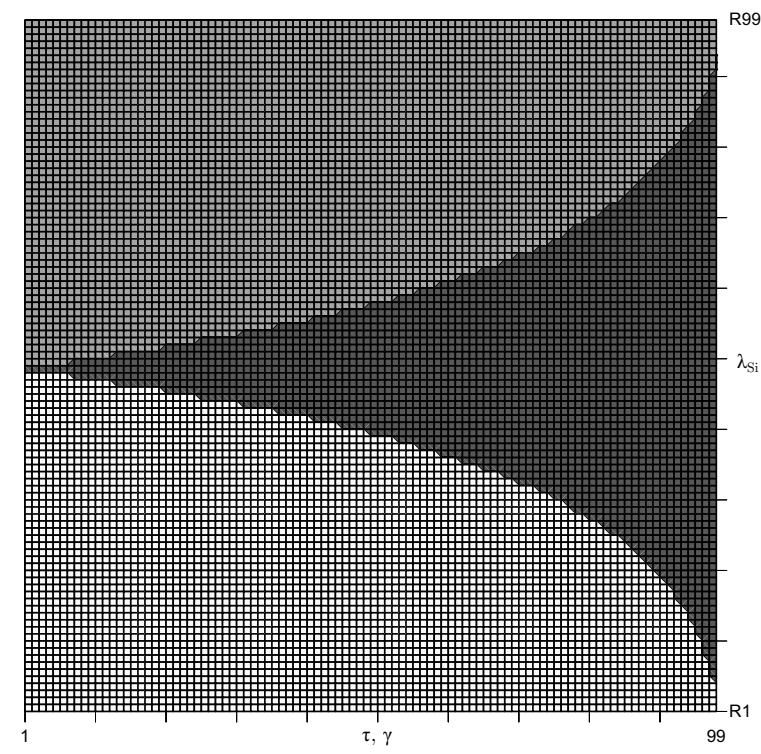

case with commuting being allowed and the one with commuting being disallowed. Note that the areas with positive or negative differences in production volumes between the commuting and the non-commuting case (see Figure 9) corresponds exactly to those areas in the factor box where skilled labor commuting occurs (see Figure 8). In other words, despite the agglomeration of people in one region, production activities remain somewhat more dispersed as commuting is introduced. Thus, also more peripheral regions are not left without any economic activity in the agglomerated equilibria as in standard NEG, which also corresponds to the observed job-decentralization by Cervero and Wu (1998). Furthermore, this result also provides some potential for regional policy measures, such as the structural funds programs by the EU (see also Gruber and Marattin, 2009, for regional policy applications of NEG). 
If the two regions are unequal in terms of their endowments with land $\left(T_{i}=0.4, T_{j}=0.6\right)$, which represents what is usually associated with the 'size' of a region, the share of $S$-commuters increases slightly if the region with less $T$ has the major part of the mobile factor ( $S$, in this case), but there are no significant qualitative changes. Accordingly, also the production volume of services in the skilled labor scarce region increases slightly with a rising share of commuters. The production of the agricultural good is more affected by unequal $T$-endowments, since land is the only input in the $Z$-sector. Thus, the share of agricultural production in a region decreases in a more pronounced way as the region hosts larger fractions of workers.

\section{Scenario 3: Migration of all Workers}

Using the same setup as before and allowing both types of labor to be mobile (i.e., to migrate), a rather strong partial agglomeration develops at all values of transport and commuting costs, while the symmetric equilibrium remains unstable. That means, the places of living of people tend to be quite agglomerated, where especially skilled workers are concentrated in one region (see Figure 10). Here, the intensity of agglomeration is over $90 \%$, i.e. over $90 \%$ of the mobile factor(s) are concentrated in one region which is due to the mobility of skilled labor.

Figure 10: Core-periphery Pattern with Mobile Skilled and Unskilled Labor and $\lambda_{T}=0.5$.

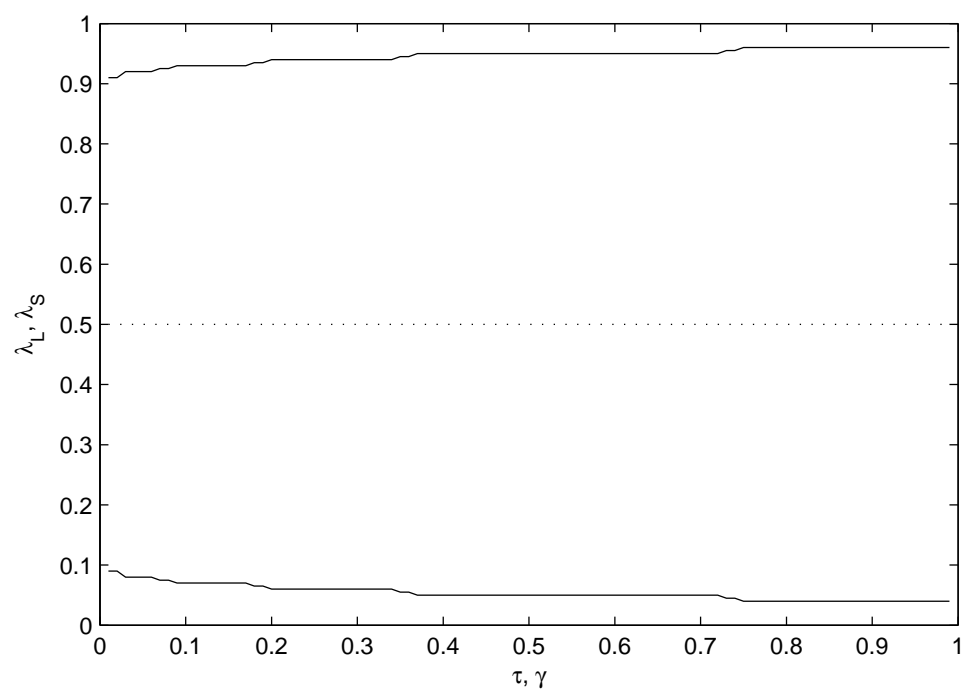

Looking at the importance of commuting, this scenario again confirms the different degrees of mobility of skilled and unskilled labor (see Figure 11). Similarly to the previous scenario with skilled labor mobility only, skilled workers commute to a larger extent as region $i$ becomes 


\section{GRUBER To Migrate or to Commute?}

large, whereas unskilled workers hardly commute. Again, this is mainly attributable to the fact that if unskilled workers do not migrate at a larger scale, they demand services in their respective home region, which in turn makes it attractive for skilled workers living in the larger region to commute to the smaller region for producing services.

Figure 11: $L$-commuters (left) and $S$-commuters (right) Corresponding to Figure 10.
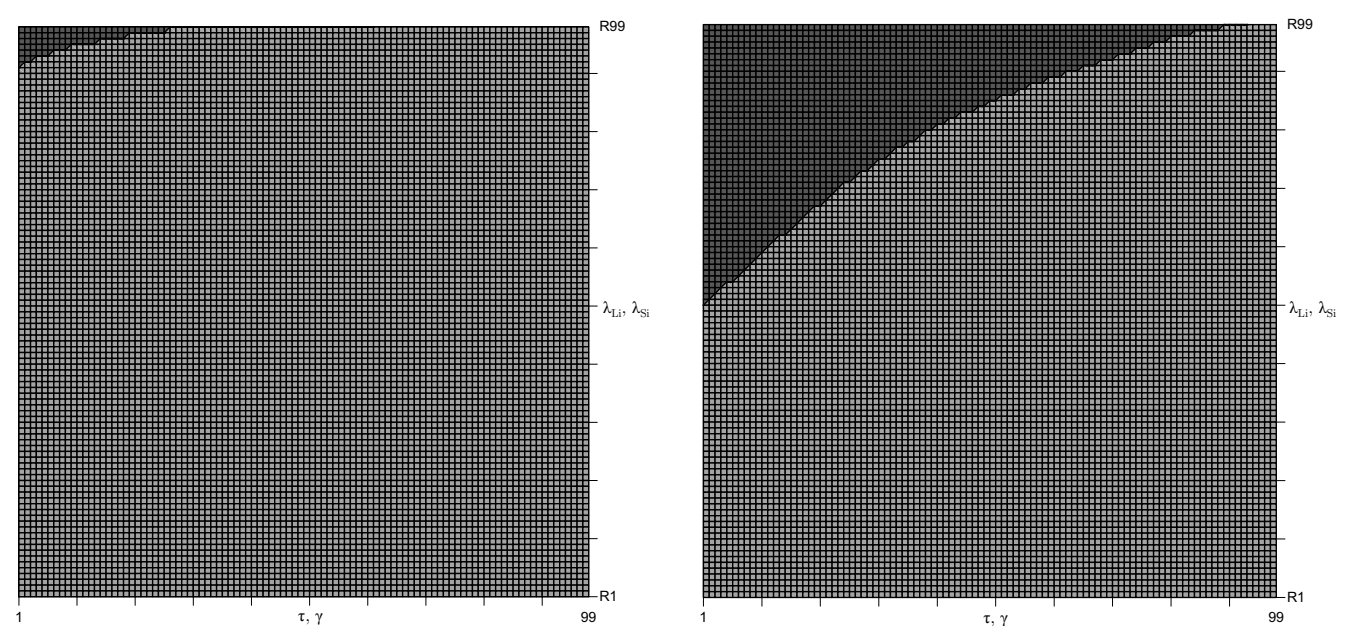

Comparing this scenario to the previous two (see Sections 4 and 5) reveals that the importance of commuting decreases to some extent. However, it remains of significant importance in the empirically relevant range of transport and commuting costs (i.e., up to about $\tau=\gamma \approx 1 / 3$ ). This is illustrated by plotting the differences in production volumes of $D$ - and $X$-goods between the cases with commuting being allowed for all workers and commuting being disallowed for all workers (see Figure 12). As in the previous scenarios, the areas with positive or negative differences in production volumes in Figure 12 mirror those situations where commuting occurs. Note that the production of services is higher in the case of commuting being allowed, whereas the production of manufacturing goods is lower. Both is a result of skilled workers (i) living in the larger region, which means they buy their manufacturing goods and some services there, and (ii) are allowed to commute, which means they buy some of their services in the smaller region and contribute to the smaller region's production of services.

Again, also this scenario confirms empirical observations of (i) commuting becoming more and more important due to decreasing 'pure' transport costs, (ii) the tendency towards urban agglomeration (see Anas, 2000), and (iii) local trends towards job decentralization and the development of sub-centers in agglomerated areas (see Cervero and $\mathrm{Wu}, 1998$ ). 
Figure 12: Difference in $D$-production Volume (left panel) and $X$-production Volume (right panel) in Region $i$ between the Commuting and the Non-commuting case, $L$ and $S$ mobile.
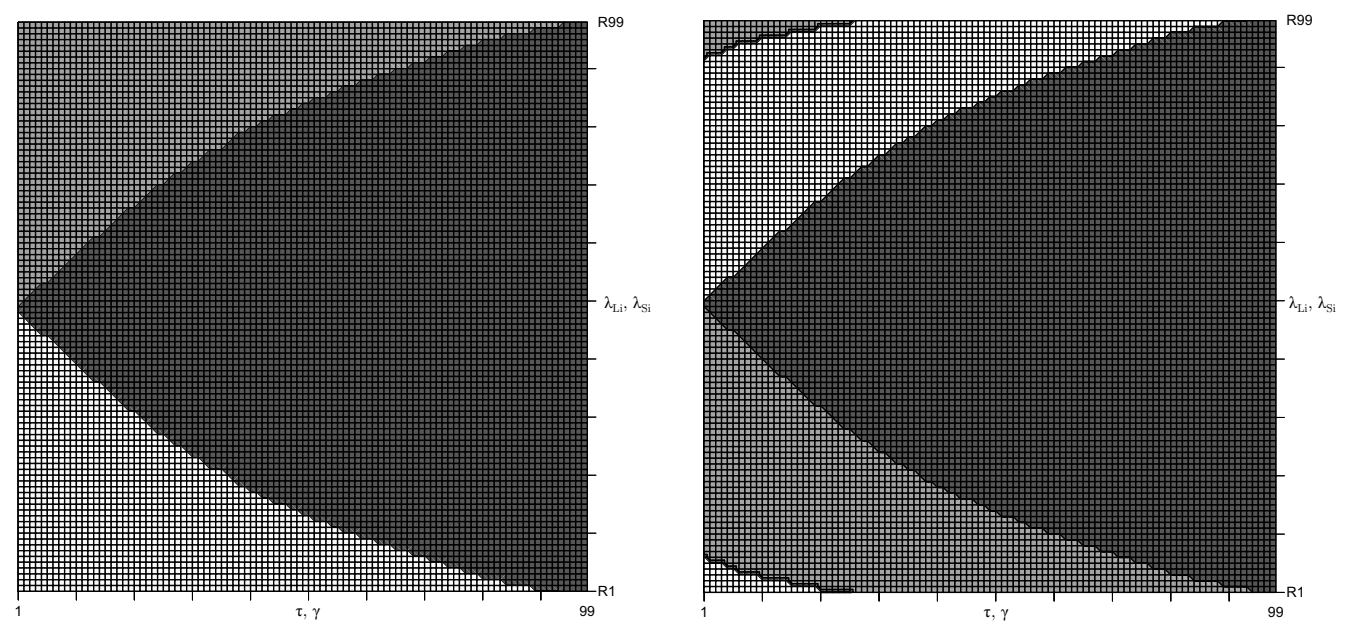

Altering the initial endowments with land $\left(T_{i}=0.4, T_{j}=0.6\right)$, leads to interesting results. Obviously, the production of agricultural goods is lower in the region with the smaller share of land. Furthermore, also the production of services is lower in that region when it hosts the major share of workers. This is due to the fact that there are less workers agglomerated due to the smaller space available in that region, which also leads to higher housing costs as the degree of agglomeration of workers increases. The small region in terms of $T$ even shows decreasing production volumes of manufacturing goods as a certain population threshold is passed (over about $70 \%$ of the total population endowment). Recalling that $X$-goods production also requires land as an input factor, scarce $T$ becomes decisive in the production of $X$ as many workers live in that region, since the workers demand land too, in order to cover their housing needs.

\section{Sensitivity Analysis}

Investigating the robustness of our results, we discuss variations of the parameters $\alpha$ and $\beta$, the income-expenditure shares for manufacturing goods and services, respectively, $\rho$, the technical rate of substitution (TRS) between input factors for $X$ - and $D$-production, and $\sigma$, the elasticity of substitution between varieties of the manufacturing good. For every new parameter value, we analyze the effects with respect to our reference cases for unskilled and skilled labor mobility, as well as for the mobility of both types of labor. These reference cases correspond to Figures 2,7 , and 10 .

As the economies become more services-oriented, i.e., lowering $\alpha$ while increasing $\beta$, the agglomeration tendency increases, since services are region-specific goods. Hence, a higher 


\section{GRUBER To Migrate or to Commute?}

income-share devoted to services leads to a higher demand of locally produced goods, and to a more pronounced agglomeration pattern due to a higher degree of inward-migration and commuting.

When changing the TRS between the input factors for the production of manufacturing goods and services $(\rho)$, we generally find that a lower $\rho$, hence a higher TRS, leads to less pronounced agglomeration patterns, since the relatively scare production factor in one region can be substituted more easily by the relatively abundant factor. This observation holds true for all of our mobility-scenarios. Moreover, it is also valid in any counterfactual where commuting is disallowed.

A higher substitutability between the varieties of the manufacturing good $(\sigma)$ leads to a very minor increase of the degree of agglomeration, whereas a lower $\sigma$ shows the opposite effect. This also holds true for all scenarios. The minor role played by changes of $\sigma$ is due to the fact that manufacturing goods make up only $40 \%$ of a consumer's bundle of goods.

Furthermore, we run counterfactual scenarios of the model with a slightly altered modelsetup with respect to commuting costs. In the counterfactuals, we let $\gamma$ assume fixed values (of $5,20,50$, and $70 \%$ of the gross wage $w_{L i}$ and/or $w_{S i}$, respectively), while leaving the introduction and simulation of transport costs $(\tau)$ unchanged, and controlled for all our three different mobility scenarios. Basically, the qualitative properties of the agglomeration patterns in all the scenarios remain valid (partial agglomeration in the $L$-mobility scenario, full agglomeration with $S$-mobility, and strong partial agglomeration with $S$ - and $L$-mobility), and the standard NEG bifurcation diagrams could again be reproduced ${ }^{18}$. The results prove to be qualitatively robust also with respect to the commuting patterns, and hence the importance of commuting in the analyzed scenarios. These counterfactual scenarios with various fixed values of commuting costs confirm the findings of Ottaviano et al. (2002), that any positive commuting costs lead to divergence at low transport costs, while agglomeration is less sustainable or optimal as transport costs become larger.

\section{Conclusions}

So far, New Economic Geography has mainly been dealing with the migration of workers, which quantitatively seems to be of less empirical relevance than commuting. Commuting has been of little importance in NEG (for the current state of research, see for instance the approaches in Murata and Thisse, 2005; Ottaviano et al., 2002; Tabuchi and Thisse, 2006), since the scope of the NEG-models is somewhat larger, i.e., they are dealing with larger geographical units (regions or countries) where commuting tends to be of less importance. The urban economics literature, on the other hand, extensively deals with commuting. Here, commuting is viewed as occurring mainly inside cities, as for instance between residential zones and the

\footnotetext{
${ }^{18}$ In order not to overload the paper, we refrain from displaying the corresponding diagrams.
} 
CBD, or investigated in its importance in terms of city-structure and city-formation (see AbdelRahman and Anas, 2004; Fujita et al., 1999; Fujita and Thisse, 2002, for an overview). Murata and Thisse (2005), Ottaviano et al. (2002), and Tabuchi and Thisse (2006) implement the urban economics approach of modelling commuting in analytically solvable NEG-frameworks.

Our approach differs from the existing literature in several respects. It aims at sticking to the NEG-literature in the line of Krugman (1991a,b) in terms of the modelling setup, while also introducing the three main sectors of an economy, agriculture, manufacturing and services, in order to obtain some hypotheses regarding the places of living and work of people, as well as on the distribution of economic activities across regions. Thus, this paper contributes to the suggestion of Fujita and Krugman (2004), to integrate urban features such as commuting into geographical models.

The main result of our analyses is that the introduction of commuting and housing costs into the NEG-model allows to disentangle the agglomeration of firms and people. Commuting allows workers to continue living in agglomerations and enjoying the benefits of a larger product variety, despite high housing costs, since they may choose to commute to another place (another region) where they receive higher net-of-commuting-costs wages, which in turn enables them to cover the high housing costs at their place of living. This observation is especially true for skilled workers, who generally are more mobile than unskilled workers.

Summarizing the findings from the three scenarios with different mobility patterns (Sections 4-6), we are generally able to show that commuting is in fact an important feature in shaping the agglomeration patterns of firms and people. We confirm several findings of Ottaviano et al. (2002), Murata and Thisse (2005), and Tabuchi and Thisse (2006) regarding the influence of commuting and transport costs on the resulting agglomeration structure. In contrast to the cited literature, we are able to achieve those results (i) without forcing consumers/workers to commute, and (ii) despite strong (or even full) agglomeration that might occur, the peripheral region is not being left without any economic activity, as in standard NEG-models.

Furthermore, we are able to confirm some empirical findings regarding the development of agglomerations. We show that the disentangling of the agglomeration of firms and people depicts the observable patterns of job-decentralization and the formation of sub-centers in agglomerated areas (see Cervero and $\mathrm{Wu}, 1998$ ), while the trend towards agglomeration (of people) in urban areas still prevails (see Anas, 2000).

\section{References}

Abdel-Rahman, Hesham M. and Alex Anas (2004), Theories of Systems of Cities, in J. Vernon Henderson and Jacques-Francois Thisse (eds.), Handbook of Regional and Urban Economics, vol. IV: Cities and Geography. Amsterdam: North Holland, 2293-2340.

Anas, Alex (2000), Vanishing Cities: What Does New Economic Geography Imply About the Efficiency of Urbanization, Journal of Economic Geography 4, 181-199. 


\section{GRUBER To Migrate or to Commute?}

Baier, Scott L. and Jeffrey H. Bergstrand (2001), The Growth of World Trade: Tariffs, Transport Costs, and Income Similarity, Journal of International Economics 53, 1-27.

Cameron, Gavin and John Muellbauer (1998), The Housing Market and Regional Commuting and Migration Choices, Scottish Journal of Political Economy 45, 420-446.

Cervero, Robert and Kang-Li Wu (1998), Sub-centring and Commuting: Evidence from the San Francisco Bay Area, 1980-90, Urban Studies 35, 1059-1076.

Cörvers, Frank and Maud Hensen (2003), The Regionalization of Labor Markets by Modeling Commuting Behavior, unpublished manuscript, Maastricht University (NL).

De Bruyne, Karolien (2006), The Location of Economic Activity. Is there a Spatial Employment Structure in Belgium?, Review of Business and Economics LI, 75-104.

Dixit, Avinash K. and Joseph E. Stiglitz (1977), Monopolistic Competition and Optimum Product Diversity, American Economic Review 67, 297-308.

The Economist (1999a), Urban Planning: A Windy City for the Next Century, April 8.

The Economist (1999b), Urban Sprawl: To Traffic Hell and Back, May 6.

Egger, Peter, Stefan Gruber, Mario Larch and Michael Paffermayr (2007), Knowledge-Capital Meets New Economic Geography, Annals of Regional Science 41, 857-875.

Eichengreen, Barry (1993), Labor Markets and European Monetary Unification, in P.R. Masson, M.P. Taylor (eds.), Policy Issues in the Operation of Currency Unions, Cambridge, MA: Cambridge University Press, 130-162.

Fujita, Masahisa (1998), Urban Economic Theory: Land Use and City Size. Cambridge, MA: Cambridge University Press.

Fujita, Masahisa, Paul Krugman and Anthony J. Venables (1999), The Spatial Economy - Cities, Regions, and International Trade. Cambridge, MA: The MIT Press.

Fujita, Masahisa and Jacques-Francois Thisse (2002), Economics of Agglomeration. Cambridge, MA: Cambridge University Press.

Fujita, Masahisa and Paul Krugman (2004), The New Economic Geography: Past, Present and Future, Papers in Regional Science 83, 139-164.

Glaeser, Edward L. and Matthew E. Kahn (2004), Sprawl and Urban Growth, in J. Vernon Henderson and Jacques-Francois Thisse (eds.), Handbook of Regional and Urban Economics, vol. IV: Cities and Geography. Amsterdam: North Holland, 2481-2528.

Glaeser, Edward, L. and Janet E. Kohlhase (2004), Cities, Regions and the Decline of Transport Costs, Papers in Regional Science 83, 197-228.

Gruber, Stefan and Luigi Marattin (2009), Taxation, Infrastructure, and Endogenous Trade Costs in New Economic Geography, Papers in Regional Science, forthcoming.

Kertesi, Gabor (2000), Migration and Commuting: Two Potential Forces Reducing Regional Inequalities in Economic Opportunities, SOCO Project Paper no. 77b, Institute for Human Sciences, Vienna. 
Krugman, Paul (1991a), Geography and Trade. Leuven: Leuven University Press, Cambridge, MA: Cambridge University Press.

Krugman, Paul (1991b), Increasing Returns and Economic Geography, Journal of Political Economy 99, 483-499.

Mascarilla Miro, Oscar and Yuri Yegorov (2005), Centrifugal Forces and Functional Urban Areas, unpublished manuscript, University of Barcelona.

Murata, Yasusada and Jacques-Francois Thisse (2005), A Simple Model of Economic Geography à la Helpman-Tabuchi, Journal of Urban Economics 58, 137-155.

Ottaviano, Gianmarco I.P. and Jacques-Francois Thisse (2002), Integration, Agglomeration and the Political Economics of Factor Mobility, Journal of Public Economics 83, 429-456.

Ottaviano, Gianmarco I.P., Takatoshi Tabuchi and Jacques-Francois Thisse (2002), Agglomeration and Trade Revisited, International Economic Review 43, 409-435.

Puga, Diego (1999), The Rise and Fall of Regional Inequalities, European Economic Review 43, 303-334.

Shields, Gail M. and Michael P. Shields (1989), The Emergence of Migration Theory and a Suggested New Direction, Journal of Economic Surveys 3, 277-304.

Tabuchi, Takatoshi and Jacques-Francois Thisse (2006), Regional Specialization, Urban Hierarchy, and Commuting Costs, International Economic Review 47, 1295-1317. 